\title{
Impact of Bronchodilator Responsiveness on Quality of Life and Exercise Capacity in Patients With COPD
}

\author{
Francisco Ortega MD, Eduardo Márquez-Martín MD, Borja Valencia MD, Pilar Cejudo MD, \\ Ana Rodriguez MD, Jose Luis López-Campos MD PhD, and Emilia Barrot MD
}

\begin{abstract}
BACKGROUND: Bronchial variability in COPD patients may be a phenotypic feature associated with clinical characteristics and differential treatment response. We analyzed whether symptoms, quality of life, and exercise capacity varied in COPD patients as a function of bronchodilator test results, and compared responses to an exercise program. METHODS: A positive bronchodilator

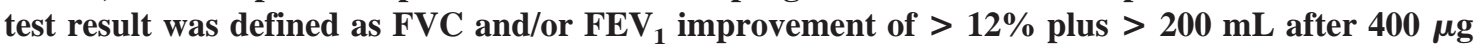
of salbutamol. We studied 198 COPD subjects: 94 with positive reversibility, and 104 with negative reversibility. Training sessions were carried out on 3 non-consecutive days each week, for 12 weeks, and consisted of a combination of resistance and strength training. Subjects were evaluated on 2 consecutive days at baseline, and at the end of the 12-week training program. RESULTS: Those with positive reversibility had shorter time to exhaustion in the endurance test $(19.1 \pm 12.6 \mathrm{~min}$ vs $24.5 \pm 14.5 \mathrm{~min}, P=.03)$, shorter shuttle walk test distance $(380.6 \pm 158.2 \mathrm{~m}$ vs $438.5 \pm 149.1 \mathrm{~m}$, $P=.02)$, and lower Chronic Respiratory Disease Questionnaire scores $(18.7 \pm 4.6$ vs $19.8 \pm 4.3$, $P=.01)$. There were no significant differences in peak exercise, peripheral muscle strength, dyspnea, or improvement after exercise training. CONCLUSIONS: Compared to COPD subjects with negative reversibility, those with positive reversibility walked for shorter distances, and had shorter endurance times and worse quality of life, but the improvements after exercise training were similar. Key words: COPD; bronchodilator; quality of life; exercise; rehabilitation. [Respir Care 2014;59(1):81-89. () 2014 Daedalus Enterprises]
\end{abstract}

\section{Introduction}

COPD is characterized by airway obstruction that is not fully reversible. Forced spirometry with a bronchodilator test is essential for the diagnosis and classification of

\footnotetext{
The authors are affiliated with the Unidad Médico-Quirúrgica de Enfermedades Respiratorias, Hospital Universitario Virgen del Rocío, Seville, Spain. Drs Ortega, Márquez-Martín, Valencia, Cejudo, Barrot, and LópezCampos are also affiliated with the Instituto de Biomedicina de Sevilla, Seville, Spain. Drs López-Campos, Ortega, and Barrot are also affiliated with the Centro de Investigación Biomédica en Red de Enfermedades Respiratorias.
}

The authors have disclosed no conflicts of interest.

Correspondence: Francisco Ortega MD, Unidad Médico-Quirúrgica de Enfermedades Respiratorias, Hospital Universitario Virgen del Rocío, Avenida de Manuel Siurot 41013, Seville, Spain. E-mail: francisco. ortega.sspa@juntadeandalucia.es.

DOI: $10.4187 /$ respcare.02399
COPD. ${ }^{1}$ The diagnosis should be confirmed by postbronchodilator spirometry, which attenuates the effect of reversibility, making it easier to distinguish between asthma, which is completely reversible, and COPD, which is not. This approach reduces the risk of misclassification. ${ }^{1}$

The airway obstruction in COPD, unlike that in asthma, is usually considered permanent or, at most, partially reversible; that is, usually little change is seen in spirometry after the administration of a bronchodilator. On the other hand, one of the main reasons for excluding patients with COPD from studies and clinical trials of drugs has been that they do show a positive response to bronchodilators or present certain clinical characteristics that, traditionally, have been associated with asthma. ${ }^{2}$

There is a need to re-evaluate the concept of asthma and COPD as separate conditions, and to consider situations when they may coexist, or when one condition may evolve into the other. The so-called overlap syndrome is recognized as the coexistence of increased variability of air flow in a patient with incompletely reversible airway obstruc- 
tion. Bronchial variability as a phenotypic feature may be present in more than half of patients with COPD. ${ }^{3}$ This subgroup showing reversibility with bronchodilators was found to have elevated eosinophil levels in induced sputum, and higher concentrations of exhaled nitric oxide. ${ }^{4}$ Some studies have found airway obstruction reversibility to be an independent positive predictor of survival, and a slower decrease in $\mathrm{FEV}_{1}$ among patients with COPD. 5 Nevertheless, patients with bronchial hyper-responsiveness have a higher risk of developing respiratory symptoms and $\mathrm{COPD}$, the annual decrease in $\mathrm{FEV}_{1}$ being higher among active smokers with bronchial hyper-responsiveness. ${ }^{6}$ Indeed, bronchial hyper-responsiveness has been found to be significantly associated with mortality due to COPD, this being directly related to the degree of histamine hyperresponsiveness. ${ }^{7}$

Patients with COPD who have a positive bronchodilator response seem to respond most often and most strongly to inhaled corticosteroids, ${ }^{8}$ the effect being longer lasting when these are combined with a long-acting betaagonist. ${ }^{9,10}$ The effect of other types of treatment in this subgroup of patients is unknown. Exercise training has been shown to increase exercise capacity, reduce dyspnea, and improve quality of life among patients with COPD. ${ }^{11}$ However, the response to such a program varies among patients. It is largely unknown which factors determine these results, but phenotypic differences could explain some of these variations. ${ }^{12}$

In particular, it is not known whether or not, among COPD patients, having a positive bronchodilator response influences important clinical outcomes and, accordingly, could be used to classify patients into different groups in terms of prognosis and appropriate treatments. Our objective was to analyze whether or not there were differences in symptoms, quality of life, and/or exercise capacity among patients with COPD as a function of their bronchodilator responsiveness, and whether this was related to their degree of airway obstruction. In addition, we assessed response to an exercise training program as a function of whether or not patients responded to bronchodilators. Our hypothesis was that quality of life and exercise capacity would be worse among COPD patients who respond positively to bronchodilators, as would response to an exercise program.

\section{Methods}

This study was approved by the clinical research ethics committee of the Hospital Universitario Virgen del Rocío, Seville, Spain, and written informed consent was obtained from each subject prior to inclusion.

\section{QUICK LOOK}

\section{Current knowledge}

COPD is characterized by airway obstruction that is not fully reversible. Pre- and post-bronchodilator spirometry is recommended for the diagnosis and classification of COPD.

\section{What this paper contributes to our knowledge}

COPD patients with positive response to a bronchodilator had lower exercise capacity, shorter 6-min walk distance, and lower quality-of-life scores, but following exercise training had results similar to patients with negative bronchodilator response.

\section{Study Subjects}

This was an uncontrolled, prospective clinical trial with a cohort of subjects with COPD, recruited when they attended the hospital for routine appointments for the evaluation of a pulmonary rehabilitation program. Inclusion criteria were: age $\geq 18$ years, COPD (diagnosed according to the international guidelines ${ }^{1}$ ), at least 20 pack-years of smoking, and clinically stable for at least the previous 3 months. Exclusion criteria were: unwillingness to participate in the study, COPD exacerbation within the past 3 months that required systemic corticosteroids or antibiotics, and any contraindication or inability to perform the study tests (eg, a history of uncontrolled heart disease or the presence of acute respiratory conditions). ${ }^{1} \mathrm{~A}$ history of asthma was defined by affirmative answers to 2 questions: Have you ever had asthma? and, Was this confirmed by a doctor? The subjects' regular medications remained unchanged, and in line with guideline recommendations. ${ }^{1}$

Spirometry was performed at baseline and $15 \mathrm{~min}$ after the administration of $400 \mu \mathrm{g}$ salbutamol, in accordance with the acceptability and reproducibility criteria of the American Thoracic Society. ${ }^{13}$ Acute bronchodilator responsiveness (positive reversibility) was defined as FVC and/or $\mathrm{FEV}_{1}$ improvement of $\geq 12 \%$ and $\geq 200 \mathrm{~mL} \cdot{ }^{1,14,15}$ We included in the analysis the data from all subjects who had $\geq 2$ valid spirometry measurements, taken at least 3 months apart; bronchodilator responsiveness had to be consistent between the measurements. We used the COPD definition and severity stratification of the Global Initiative for Chronic Obstructive Lung Disease (GOLD): postbronchodilator $\mathrm{FEV}_{1} / \mathrm{FVC}<0.70 .{ }^{1}$

\section{Training Program}

Training sessions were carried out on 3 nonconsecutive days each week, for 12 weeks. The duration of sessions 
was 40-min plus a 10-min warm-up and 10-min cool down. The training program was structured as reported previously, ${ }^{12}$ and consisted of combined resistance and strength training. The endurance training consisted of leg exercise on a calibrated ergocycle (Ergometer ZX1, Kettler Sport, Ense, Germany) at a fixed pedaling speed $(60 \mathrm{rpm})$, with which we measure the work rate (in watts) achieved by the subject during each session. The physiotherapist was aware of the training intensity prescribed for each subject, and encouraged him/her to reach it. The work rate corresponding to $70 \%$ of the peak work rate achieved during the baseline incremental exercise test was selected as the target training intensity. ${ }^{16,17}$ The strength training included the following exercises, with weight-lifting equipment (Fitness-Center Classic, Kettler Sport, Ense, Germany): chest pull (mainly for strengthening of the latissimus dorsi); butterfly (mainly for the pectoralis major muscle); neck press (mainly for the triceps brachii and deltoid); leg flexion (mainly for the biceps femoris and grastrocnemius); and leg extension (mainly for the quadriceps femoris). The subjects performed 4 series of 6 to 8 repetitions for each of the exercises, at a work load of $70-85 \%$ of the 1 repetition maximum. This test was repeated every 2 weeks for new adjustments of the work load.

\section{Measurement Tools}

Subjects were evaluated on 2 consecutive days at baseline, and at the end of the 12-week training program. Preand post-training tests were performed under similar conditions. The shuttle walk test and the submaximal endurance cycle test were primary outcome measures for this study. Secondary outcome measures were the pulmonary function studies, maximal cycle exercise test, peripheral muscle strength, quality of life, and dyspnea.

Pulmonary Function Tests. Spirometry (Masterlab, Erich Jaeger, Friedberg, Germany) was per the Sociedad Española de Neumología y Cirugía Torácica ${ }^{18}$ and American Thoracic Society recommendations. ${ }^{13}$ Lung volumes (functional residual capacity, residual volume, and total lung capacity) were determined plethysmographically, with the interruption technique. ${ }^{19}$ Carbon monoxide diffusion constant was measured with the single-breath method (Masterlab, Erich Jaeger, Friedberg. Germany). We measured arterial blood gases $\left(\mathrm{pH}, \mathrm{P}_{\mathrm{aO}_{2}}, \mathrm{P}_{\mathrm{aCO}_{2}}\right)$ at rest $(\mathrm{ABL} 500$, Radiometer, Copenhagen, Denmark), and maximum respiratory pressures (Manometer 163, SibelMed, Barcelona, Spain). Nutritional status was evaluated by calculating the body mass index. A body mass index below $21 \mathrm{~kg} / \mathrm{m}^{2}$ was considered underweight. ${ }^{20}$

Maximal Cardiopulmonary Exercise Test. Maximal cardiopulmonary exercise testing was performed on a cy- cle ergometer (Ergomed, Siemens, Berlin, Germany) as previously described ${ }^{21}$ and according to the international standards. ${ }^{16}$ Maximal exercise tolerance was measured with a symptom-limited graded exercise test performed while the subject was breathing room air. Breathing was continuously monitored, and inhaled and exhaled gases were collected and analyzed for oxygen consumption and carbon dioxide production. The level of resistance was then increased by $10-15$ watts every minute, until the maximal exercise level was reached. ${ }^{22}$ Electrocardiogram, heart rate, and $\mathrm{S}_{\mathrm{pO}_{2}}$ were monitored during exercise. All measurements were integrated into the cycle ergometer and evaluated simultaneously during the test. After the exercise we assessed heart rate, blood pressure, leg fatigue, and dyspnea (with the modified Borg scale). ${ }^{23}$

Submaximal Cycle Test. The submaximal endurance test was performed with the cycle ergometer set at $70 \%$ of the maximum power reached by each subject in the previous maximal test. The endurance time, saturation, and heart rate were monitored.

Shuttle Walk Test. The shuttle walk test was conducted as described by Singh et al. ${ }^{24}$ The subject walks up and down a $10 \mathrm{~m}$ course marked by 2 cones inset $0.5 \mathrm{~m}$ from either end, to avoid abrupt changes in direction. There were a maximum of 12 progressive levels (or speeds), lasting for $1 \mathrm{~min}$ each. The subject aims to be at the opposite end to the start by the time the bleep sounds. Maximum level reached, distance walked, blood pressure, heart rate, and dyspnea (with the modified Borg scale) ${ }^{23}$ were measured at the end of the exercise.

Peripheral Muscle Strength. The 1-repetition maximum test was used for measuring peripheral muscle strength. ${ }^{25}$ This test measures the maximum amount of weight the subject can lift (Fitness-Center Classic, Kettler Sport, Ense, Germany) in a single movement, in the chest pull, butterfly, shoulder press, leg extension, and leg curl exercises.

Dyspnea Score. Baseline dyspnea was evaluated with the Mahler Baseline and Transitional Dyspnea Indexes, ${ }^{26}$ and the modified Medical Research Council (MRC) dyspnea scale. ${ }^{27}$ The Baseline and Transitional Dyspnea Indexes have 3 domains: functional impairment, which determines the impact of breathlessness on the ability to carry out activities; magnitude of task, which determines the type of task that causes breathlessness; and magnitude of effort, which establishes the level of effort that results in breathlessness. A 1-unit change in Transitional Dyspnea Index was taken as the minimum clinically important change. The MRC dyspnea scale is a 5-point scale (from 0 to 4 ), based on degrees of various physical activities that precipitate dyspnea. 
Table 1. Baseline Clinical and Functional Characteristics

\begin{tabular}{|c|c|c|c|c|}
\hline & $\begin{array}{c}\text { All } \\
\text { Subjects } \\
n=198\end{array}$ & $\begin{array}{c}\text { Positive } \\
\text { Reversibility } \\
n=94\end{array}$ & $\begin{array}{c}\text { Negative } \\
\text { Reversibility } \\
n=104\end{array}$ & $P^{*}$ \\
\hline Age, y & $65 \pm 7.6$ & $66 \pm 6.1$ & $64 \pm 7.2$ & .54 \\
\hline Body mass index, $\mathrm{kg} / \mathrm{m}^{2}$ & $29.5 \pm 4.8$ & $28.9 \pm 5.2$ & $29.9 \pm 3.9$ & .93 \\
\hline FVC, $\%$ predicted & $84.5 \pm 14.9$ & $83.2 \pm 13.2$ & $85.1 \pm 15.1$ & .39 \\
\hline $\mathrm{FEV}_{1}, \%$ predicted & $42.7 \pm 13.5$ & $41.5 \pm 15.6$ & $44.1 \pm 14.2$ & .31 \\
\hline Residual volume, $\%$ predicted & $162 \pm 32.7$ & $155.2 \pm 28.2$ & $169.1 \pm 40.1$ & .07 \\
\hline Total lung capacity, $\%$ predicted & $114 \pm 13.8$ & $113.8 \pm 12.9$ & $114.7 \pm 15.1$ & .08 \\
\hline Carbon monoxide diffusion constant, $\%$ predicted & $70.6 \pm 25.1$ & $71.4 \pm 26.1$ & $69.8 \pm 24.2$ & .99 \\
\hline $\mathrm{P}_{\mathrm{aO}_{2}}, \mathrm{~mm} \mathrm{Hg}$ & $71 \pm 9$ & $70 \pm 10$ & $71 \pm 10$ & .18 \\
\hline $\mathrm{P}_{\mathrm{aCO}_{2}}, \mathrm{~mm} \mathrm{Hg}$ & $41.9 \pm 5.4$ & $42.2 \pm 5.3$ & $40 \pm 4.9$ & .26 \\
\hline
\end{tabular}

Quality of Life. Quality of life was evaluated with the Chronic Respiratory Disease Questionnaire, which is a disease-specific quality-of-life questionnaire that has been translated to and validated in Spanish. ${ }^{28,29}$ The questionnaire is made up of 20 items in 4 domains: dyspnea or breathing difficulty, fatigue, emotional function, and mastery. A change of 0.5 units is taken as the minimum clinically important change.

\section{Statistical Analysis}

Statistical analysis was performed with statistics software (PASW 18.0, IBM, Armonk, New York). Qualitative variables are presented as number and percent, and quantitative variables as mean \pm SD. Differences between groups (positive reversibility vs negative reversibility in the groups, and subgroups by degree of obstruction) were assessed with the Student $t$ test (for quantitative variables) or the Mann-Whitney U test (for ordinal variables). The pre- versus post-training differences were assessed with the paired Student $t$ test (for quantitative variables) or Wilcoxon test (for ordinal variables). Differences were considered statistically significant at $P<.05$.

\section{Results}

We enrolled 198 subjects: all former smokers. Of these, 94 had air-flow obstruction with positive reversibility (92 by change in $\mathrm{FEV}_{1}$ ), and 104 had negative reversibility. All the subjects had moderate to severe obstruction, with no significant differences between the 2 groups (Table 1 ).

Table 2. Baseline Exercise Capacity and Strength

\begin{tabular}{|c|c|c|c|c|}
\hline & $\begin{array}{c}\text { All } \\
\text { Subjects } \\
n=198\end{array}$ & $\begin{array}{c}\text { Positive } \\
\text { Reversibility } \\
n=94\end{array}$ & $\begin{array}{c}\text { Negative } \\
\text { Reversibility } \\
n=104\end{array}$ & $P^{*}$ \\
\hline Load, watts & $63.5 \pm 23$ & $65.1 \pm 21.9$ & $61.9 \pm 22.2$ & .45 \\
\hline Load, \% & $45.8 \pm 15.4$ & $47.2 \pm 16.2$ & $44.8 \pm 15.6$ & .97 \\
\hline Peak $\dot{\mathrm{V}}_{\mathrm{O}_{2}}, \%$ predicted & $56.5 \pm 14.8$ & $54.8 \pm 15.4$ & $57.9 \pm 16.5$ & .46 \\
\hline Peak $\dot{\mathrm{V}}_{\mathrm{O}_{2}}, \mathrm{~mL} / \mathrm{min} / \mathrm{kg}$ & $16.2 \pm 6.8$ & $15.8 \pm 7.2$ & $16.7 \pm 7.6$ & .11 \\
\hline Shuttle-walk distance, $\mathrm{m}$ & $410 \pm 152$ & $380.6 \pm 158.2$ & $438.5 \pm 149.1$ & .02 \\
\hline Endurance, $\min$ & $21.8 \pm 13.5$ & $19.1 \pm 12.6$ & $24.5 \pm 14.5$ & .03 \\
\hline Chest-pull, kg & $44.5 \pm 9.8$ & $45.1 \pm 9$ & $43.7 \pm 10.2$ & .83 \\
\hline Butterfly, kg & $20 \pm 7$ & $19.4 \pm 8.1$ & $21 \pm 9.2$ & .78 \\
\hline Neck-press, kg & $23 \pm 6.2$ & $23.4 \pm 7.2$ & $22.4 \pm 5.2$ & .65 \\
\hline Leg extension, $\mathrm{kg}$ & $38,5 \pm 11.4$ & $36.8 \pm 10.4$ & $40.2 \pm 11.6$ & .71 \\
\hline Leg flexion, $\mathrm{kg}$ & $17.6 \pm 5.2$ & $18.2 \pm 5.6$ & $17.1 \pm 4.2$ & .76 \\
\hline \multicolumn{5}{|c|}{$\begin{array}{l}\text { Values are mean } \pm \text { SD. } \\
{ }^{*} \text { For positive reversibility vs negative reversibility. } \\
\dot{\mathrm{V}}_{\mathrm{O}_{2}}=\text { oxygen uptake }\end{array}$} \\
\hline
\end{tabular}


Table 3. Baseline Dyspnea and Health Status Scores

\begin{tabular}{|c|c|c|c|c|}
\hline & $\begin{array}{c}\text { All } \\
\text { Subjects } \\
n=198\end{array}$ & $\begin{array}{c}\text { Positive } \\
\text { Reversibility } \\
n=94\end{array}$ & $\begin{array}{c}\text { Negative } \\
\text { Reversibility } \\
n=104\end{array}$ & $P^{*}$ \\
\hline Medical Research Council dyspnea score & $2.2 \pm 0.9$ & $2.2 \pm 0.8$ & $2.1 \pm 1$ & .53 \\
\hline \multicolumn{5}{|c|}{ Chronic Respiratory Disease Questionnaire scores } \\
\hline Dyspnea & $3.9 \pm 0.8$ & $3.8 \pm 0.8$ & $4.1 \pm 0.7$ & .14 \\
\hline Fatigue & $5.4 \pm 0.9$ & $5.2 \pm 1$ & $5.6 \pm 0.8$ & .04 \\
\hline Emotional function & $4.8 \pm 0.9$ & $4.7 \pm 0.9$ & $5 \pm 0.8$ & .03 \\
\hline Mastery & $5.1 \pm 1$ & $5 \pm 1$ & $5.1 \pm 0.9$ & .47 \\
\hline Total & $19.2 \pm 4$ & $18.7 \pm 4.6$ & $19.8 \pm 4.3$ & .01 \\
\hline \multicolumn{5}{|l|}{ Baseline Dyspnea Index scores } \\
\hline Magnitude of task & $2.3 \pm 0.8$ & $2.2 \pm 0.9$ & $2.3 \pm 1$ & .63 \\
\hline Functional impairment & $2.1 \pm 0.9$ & $2.1 \pm 1$ & $2 \pm 0.8$ & .31 \\
\hline Magnitude of effort & $2.2 \pm 0.9$ & $2.1 \pm 0.7$ & $2.3 \pm 1$ & .53 \\
\hline Focal score & $6.5 \pm 2.5$ & $6.4 \pm 2.7$ & $6.6 \pm 2.8$ & .51 \\
\hline
\end{tabular}

Overall, 47 subjects had a history of asthma, and 33 of these had positive reversibility $(P<.001)$.

We found no significant differences in peak exercise capacity or muscle strength between the subjects with and without reversibility (Table 2). On the other hand, those with positive reversibility had a significantly shorter time to exhaustion in the endurance test $(19.1 \pm 12.6 \mathrm{~min}$ vs $24.5 \pm 14.5 \mathrm{~min}, P=.03$ ), and a shorter shuttle-walk distance test ( $380.6 \pm 158.2 \mathrm{~m}$ vs $438.5 \pm 149.1 \mathrm{~m}, P=.02)$ (see Table 2). There were no significant differences in the degree of dyspnea (MRC dyspnea score or Baseline Dyspnea Index) between the groups. Nevertheless, the positive reversibility subjects had a lower total Chronic Respiratory Disease Questionnaire score (18.7 \pm 4.6 vs $19.8 \pm 4.3$, $P=.01$ ), mainly due to significantly lower fatigue and emotional function scores (Table 3).

Considering the subjects by degree of obstruction, 71 were classified as GOLD stage II (33 with positive revers-

Table 4. Exercise Capacity, Strength, Dyspnea, and Health Status Versus GOLD Stage and Bronchodilator Reversibility

\begin{tabular}{|c|c|c|c|c|c|c|c|c|c|}
\hline & \multicolumn{3}{|c|}{ GOLD Stage II $(n=71)$} & \multicolumn{3}{|c|}{ GOLD Stage III $(n=65)$} & \multicolumn{3}{|c|}{ GOLD Stage IV $(n=62)$} \\
\hline & $\begin{array}{c}\text { Positive } \\
\text { Reversibility } \\
n=33\end{array}$ & $\begin{array}{c}\text { Negative } \\
\text { Reversibility } \\
n=38\end{array}$ & $P$ & $\begin{array}{c}\text { Positive } \\
\text { Reversibility } \\
n=31\end{array}$ & $\begin{array}{c}\text { Negative } \\
\text { Reversibility } \\
n=34\end{array}$ & $P$ & $\begin{array}{c}\text { Positive } \\
\text { Reversibility } \\
n=30\end{array}$ & $\begin{array}{c}\text { Negative } \\
\text { Reversibility } \\
n=32\end{array}$ & $P$ \\
\hline Load, watts & $86.4 \pm 17.2$ & $84 \pm 18.1$ & .50 & $62.5 \pm 15$ & $58.7 \pm 16.2$ & .13 & $46.5 \pm 11.7$ & $42.9 \pm 13.2$ & .91 \\
\hline Peak $\dot{\mathrm{V}}_{\mathrm{O}_{2}}, \mathrm{~mL} / \mathrm{min} / \mathrm{kg}$ & $21.1 \pm 6.1$ & $22.9 \pm 5.4$ & .97 & $15.1 \pm 5.2$ & $16.2 \pm 4.8$ & .37 & $10.7 \pm 4.6$ & $11 \pm 3.8$ & .34 \\
\hline Shuttle-walk distance, $\mathrm{m}$ & $474.2 \pm 120$ & $557.6 \pm 126$ & $<.001$ & $398.3 \pm 94$ & $459.8 \pm 105$ & .02 & $270 \pm 86$ & $298 \pm 92$ & .34 \\
\hline Endurance, min & $24.5 \pm 9.9$ & $33.3 \pm 8.6$ & $<.001$ & $18.3 \pm 7.2$ & $23.7 \pm 6.5$ & .005 & $14.4 \pm 7.6$ & $16.5 \pm 9.4$ & .65 \\
\hline Chest-pull, kg & $52.9 \pm 6.5$ & $53.4 \pm 7.2$ & .87 & $46.4 \pm 6.6$ & $44.5 \pm 8.1$ & .31 & $35.7 \pm 5.9$ & $33.8 \pm 7.1$ & .32 \\
\hline Butterfly, kg & $27.3 \pm 4.2$ & $26.5 \pm 4.8$ & .36 & $18.5 \pm 4.6$ & $21.9 \pm 5.1$ & .91 & $12.4 \pm 4.3$ & $14.4 \pm 4.2$ & .81 \\
\hline Neck-press, kg & $30.4 \pm 4.5$ & $28.15 \pm 6.2$ & .16 & $21.9 \pm 4.8$ & $22.1 \pm 4.1$ & .10 & $17.6 \pm 3.5$ & $16.5 \pm 3.8$ & .32 \\
\hline Leg extension, $\mathrm{kg}$ & $48.2 \pm 5.4$ & $51.5 \pm 4.9$ & .74 & $35.1 \pm 5.1$ & $38.6 \pm 4.2$ & .18 & $27.3 \pm 5.1$ & $29.9 \pm 3.2$ & .17 \\
\hline Leg flexion, $\mathrm{kg}$ & $24.9 \pm 3.1$ & $22.6 \pm 3.9$ & .97 & $17.2 \pm 4.2$ & $16 . \pm 3.9$ & .14 & $12.4 \pm 3.8$ & $12.8 \pm 4.1$ & .65 \\
\hline $\begin{array}{l}\text { Chronic Respiratory } \\
\text { Disease Questionnaire } \\
\text { total score }\end{array}$ & $22.2 \pm 3.8$ & $24.1 \pm 2.1$ & $<.001$ & $18.5 \pm 3.2$ & $19.7 \pm 3.2$ & $<.001$ & $15.1 \pm 3.1$ & $15.4 \pm 3.2$ & .35 \\
\hline $\begin{array}{l}\text { Baseline Dyspnea Index } \\
\text { focal score }\end{array}$ & $9.2 \pm 1.8$ & $9.3 \pm 1.7$ & .14 & $6.1 \pm 2.1$ & $6.2 \pm 1.9$ & .23 & $3.9 \pm 0.8$ & $4.1 \pm 1.1$ & .69 \\
\hline $\begin{array}{l}\overline{\text { Values are mean } \pm \mathrm{SD}} \text {. } \\
\mathrm{GOLD}=\text { Global Initiative for } \mathrm{Ch} \\
\dot{\mathrm{V}}_{\mathrm{O}_{2}}=\text { oxygen uptake }\end{array}$ & c Obstructive Lu & isease & & & & & & & \\
\hline
\end{tabular}


Table 5. Response to Exercise Training

\begin{tabular}{|c|c|c|c|}
\hline & $\begin{array}{c}\text { Before } \\
\text { Exercise } \\
\text { Training }\end{array}$ & $\begin{array}{c}\text { After } \\
\text { Exercise } \\
\text { Training }\end{array}$ & $P$ \\
\hline $\mathrm{FVC}, \%$ predicted & $84.5 \pm 14.9$ & $84.1 \pm 15.2$ & .14 \\
\hline $\mathrm{FEV}_{1}, \%$ predicted & $42.7 \pm 13.5$ & $42.9 \pm 14.1$ & .37 \\
\hline Load, watts & $63.5 \pm 23$ & $79.2 \pm 19.5$ & .04 \\
\hline Peak $\dot{\mathrm{V}}_{\mathrm{O}_{2}}, \mathrm{~mL} / \mathrm{min} / \mathrm{kg}$ & $16.2 \pm 6.8$ & $18.9 \pm 5.1$ & .04 \\
\hline Shuttle walk test distance, $\mathrm{m}$ & $410 \pm 152$ & $501.4 \pm 108$ & $<.001$ \\
\hline Endurance, $\min$ & $21.8 \pm 13.5$ & $43.3 \pm 15.4$ & $<.001$ \\
\hline Chest-pull, kg & $44.5 \pm 9.8$ & $55.2 \pm 7.8$ & .005 \\
\hline Butterfly, kg & $20 \pm 7$ & $26.7 \pm 5.5$ & .03 \\
\hline Neck-press, kg & $23 \pm 6.2$ & $30.3 \pm 5.1$ & .02 \\
\hline Leg extension, $\mathrm{kg}$ & $38.5 \pm 11.4$ & $51.9 \pm 9.5$ & .005 \\
\hline Leg flexion, $\mathrm{kg}$ & $17.6 \pm 5.2$ & $26.9 \pm 5.6$ & .005 \\
\hline Chronic Respiratory Disease Questionnaire total score & $19.2 \pm 4$ & $22.9 \pm 3.2$ & .04 \\
\hline $\begin{array}{l}\text { Values are mean } \pm \text { SD. } \\
\dot{\mathrm{V}}_{\mathrm{O}_{2}}=\text { oxygen uptake }\end{array}$ & & & \\
\hline
\end{tabular}

ibility), 65 were classified as GOLD stage III (31 with positive reversibility), and 62 were classified as GOLD stage IV (30 with positive reversibility). Among the GOLD stage II and III subjects there were significant differences between the positive and negative reversibility subgroups in time to exhaustion in the endurance test, shuttle-walk distance, and Chronic Respiratory Disease Questionnaire total score (Table 4), but no significant differences in those variables between the positive and negative reversibility subjects classified as GOLD stage IV, and none at any of the GOLD stages in peak exercise capacity, peripheral muscle strength, MRC dyspnea score, or Baseline Dyspnea Index.

Of all the subjects, 169 completed the exercise training program, and 81 had positive reversibility. After exercise training all the subjects had improved in dyspnea, exercise, and strength parameters (Table 5). The mean posttraining changes are summarized in Table 6 . All the posttraining improvements were similar in the positive and negative reversibility subgroups, there being no significant differences in the improvements achieved in any of the variables.

Table 6. Changes After Exercise Training, According to Bronchodilator Reversibility

\begin{tabular}{|c|c|c|c|c|}
\hline & \multicolumn{3}{|c|}{$\begin{array}{c}\text { Change After Exercise Training } \\
\text { mean } \pm \mathrm{SD}\end{array}$} & \multirow[b]{2}{*}{$P$} \\
\hline & $\begin{array}{c}\text { All } \\
\text { Subjects } \\
n=169\end{array}$ & $\begin{array}{c}\text { Positive } \\
\text { Reversibility } \\
n=81\end{array}$ & $\begin{array}{c}\text { Negative } \\
\text { Reversibility } \\
n=88\end{array}$ & \\
\hline Load, watts & $15.7 \pm 16.1$ & $15.4 \pm 16.6$ & $15.9 \pm 15.7$ & .87 \\
\hline Load, \% predicted & $10.6 \pm 11.6$ & $9.8 \pm 10.4$ & $11.3 \pm 12.5$ & .97 \\
\hline Peak $\dot{\mathrm{V}}_{\mathrm{O}_{2}}, \%$ predicted & $8.5 \pm 10.6$ & $9.2 \pm 10.1$ & $7.9 \pm 8.3$ & .16 \\
\hline Peak $\dot{\mathrm{V}}_{\mathrm{O}_{2}}, \mathrm{~mL} / \mathrm{min} / \mathrm{kg}$ & $2.7 \pm 3.4$ & $2.9 \pm 3.1$ & $2.5 \pm 3.5$ & .74 \\
\hline Shuttle walk distance, $\mathrm{m}$ & $91.4 \pm 64.7$ & $87.4 \pm 68.3$ & $95.5 \pm 66.6$ & .13 \\
\hline Endurance, min & $21.5 \pm 17.4$ & $21.2 \pm 18.7$ & $21.8 \pm 16.5$ & .91 \\
\hline Chest-pull, kg & $10.7 \pm 5.9$ & $11.5 \pm 5.6$ & $9.9 \pm 6.4$ & .14 \\
\hline Butterfly, kg & $6.75 \pm 4.1$ & $6.9 \pm 4.1$ & $6.6 \pm 4.3$ & .69 \\
\hline Neck-press, kg & $7.3 \pm 4.1$ & $7.1 \pm 4.6$ & $7.4 \pm 3.9$ & .35 \\
\hline Leg extension, $\mathrm{kg}$ & $13.4 \pm 7.6$ & $13.6 \pm 8.6$ & $13.2 \pm 7.1$ & .85 \\
\hline Leg flexion, $\mathrm{kg}$ & $9.3 \pm 6.1$ & $9.5 \pm 5.9$ & $9.1 \pm 6.3$ & .23 \\
\hline Medical Research Council dyspnea score & $-0.8 \pm 0.7$ & $-0.9 \pm 0.6$ & $-0.7 \pm 0.8$ & .91 \\
\hline Transitional Dyspnea Index & $4.7 \pm 1.9$ & $4.6 \pm 1.8$ & $4.8 \pm 1.7$ & .34 \\
\hline $\begin{array}{c}\text { Chronic Respiratory Disease } \\
\text { Questionnaire total score }\end{array}$ & $3.7 \pm 2.5$ & $3.8 \pm 2.4$ & $3.5 \pm 2.5$ & .13 \\
\hline
\end{tabular}




\section{Discussion}

Our findings indicate that COPD patients with positive reversibility have a shorter time to exhaustion in endurance exercise testing, and a shorter shuttle-walk distance. These differences were statistically significant between the GOLD stage II versus III subjects. The degree of dyspnea was not significantly different, but the Chronic Respiratory Disease Questionnaire score was significantly lower among the positive reversibility subjects. The post-training improvements in exercise capacity, muscle strength, Baseline and Transitional Dyspnea Indexes, MRC dyspnea score, and Chronic Respiratory Disease Questionnaire were similar in the 2 groups.

Given the heterogeneity of COPD, the evaluation of patients with COPD is changing, moving toward the idea of classifying COPD patients into subgroups. It is possible that the current concept of COPD embraces patients with common clinical and/or biological characteristics but who have different prognoses or require different types of treatment. The definition of clinical phenotype should include any characteristic(s) of the illness in which there may be differences between patients with COPD and which may be associated with different clinical outcomes. ${ }^{30}$ These characteristics must not be present in all patients, so the characteristics can be used as a basis for distinguishing subgroups. For some time it has been known that some COPD patients have some bronchodilator reversibility, and that such patients usually have elevated eosinophils in induced sputum, a higher concentration of exhaled nitric oxide, ${ }^{4}$ and respond better to corticosteroids, ${ }^{8,9}$ which are all characteristics of asthma. On the other hand, some patients diagnosed with severe asthma, many being smokers, respond less well to corticosteroids than other patients with asthma, and share other characteristics with COPD patients, such as a high neutrophil count and increased oxidative stress. ${ }^{31}$

It is well known that $70-90 \%$ of patients with asthma have exercise-induced bronchospasm. These "attacks" are more severe with continuous, prolonged exercise, and have been blamed on increased inflammation with heat and water loss on the surface of the respiratory tract. ${ }^{14,32}$ On the other hand, in some COPD patients it is possible to increase exercise capacity with bronchodilator. ${ }^{33}$ The shuttle walk test seems to be more sensitive to changes in postbronchodilator exercise tolerance than is cycling performance $^{34}$ or the 6-min walk test. ${ }^{35}$

Our COPD subjects with positive reversibility had lower exercise capacity than the negative reversibility subjects, and this was manifested in both time to exhaustion and shuttle-walk distance, above all among those in moderate to severe stages of the disease. The difference in the shut- tle walk test exceeded the threshold for clinical importance established for the test. ${ }^{36}$ In relation to this we could speculate that there was more severe airway inflammation in this subgroup. Exercise capacity is an important parameter, given its independent association with mortality, ${ }^{37}$ the association being stronger than with peak oxygen uptake measured at maximal exercise. ${ }^{38}$

The bronchodilator test is not considered to have prognostic value in patients with COPD, because the results are not sufficiently stable over time. Calverley et al, ${ }^{39}$ analyzing data from the Inhaled Steroids in Obstructive Lung Disease in Europe (ISOLDE) study, concluded that classifying subjects by positive or negative bronchodilator test was not reliable, because in moderate to severe COPD bronchodilator responsiveness is a continuous variable. However, in that study the subjects with more than $10 \%$ reversibility in the first bronchodilator test were excluded, meaning that the most reversible were omitted, so those results cannot be extrapolated to all COPD patients. Moreover, most subjects had reversibility close to the threshold $(12 \%)$, and so were more vulnerable to the influence of biological variation. Also, the 3 bronchodilator tests were carried out with different protocols, so it not surprising that the results differed. On the other hand, the fact that a characteristic or phenotype changes over time does not mean that it is not interesting. Hurst et $\mathrm{al},{ }^{40}$ analyzing the "exacerbation" phenotype in COPD subjects, confirmed that $30-40 \%$ initially classified as having the "exacerbation" phenotype did not have the necessary characteristics during the second year of follow-up.

Subjects with the most severe bronchial hyper-reactivity are predisposed to more respiratory symptoms. ${ }^{6}$ Our positive reversibility subjects did not have more dyspnea than those with negative reversibility, but did have worse quality-of-life scores, indicating worse control of their COPD, probably influenced by their lower exercise capacity. Their quality-of-life scores differed by $>0.5$ units, which is the minimum clinically important difference. ${ }^{41}$ The finding that this difference disappeared among GOLD stage IV subjects may indicate that reversibility has less effect with increasing obstruction and age. ${ }^{42}$ Further, in GOLD stage IV patients corticosteroids are more commonly used, which may mean that the disease is better controlled. In relation to this, COPD subjects with positive reversibility seem to respond better to inhaled corticosteroids. ${ }^{8}$ The influence of other types of treatments is unknown. Exercise training improves COPD symptoms and exercise capacity, though the effect differs between patients. ${ }^{11,12}$ According to our results, inhaled corticosteroids can improve a range of clinical and functional parameters in patients with COPD, regardless of their bronchodilator responsiveness. 


\section{IMPACT OF BRONCHODILATOR RESPONSIVENESS ON QUALITY OF LIFE AND EXERCISE CAPACITY}

\section{Limitations}

Probably the patient profile with bronchial hyperresponsiveness may be completed with other tests such as methacholine or exhaled nitric oxide. We relate worse exercise capacity to increased inflammation in the airways; to intentionally study this relation in terms of inflammatory markers would be a useful objective in further studies. Furthermore, although our training program is widely used in patients with COPD, we cannot ensure that other programs can find differences in response in patients with and without reversibility. Further studies could clarify these points.

\section{Conclusions}

COPD patients with positive bronchodilator reversibility could be a subgroup with different characteristics. They have lower exercise capacity, shorter shuttle-walk distance, and worse quality-of-life scores. Nevertheless, with exercise training they achieve a similar degree of improvement in several parameters to those with negative bronchodilator reversibility. This does not, however, rule out differences in their response to other types of treatment.

\section{REFERENCES}

1. Rabe KF, Hurd S, Anzueto A, Barnes PJ, Buist AS, Calverley P, et al. Global strategy for the diagnosis, management and prevention of chronic obstructive pulmonary disease. NHLBI/WHO Global Initiative for chronic obstructive pulmonary disease (GOLD). Workshop summary Am J Respir Crit Care Med 2007;176(6):532-555.

2. Tashkin DP, Celli B, Decramer M, Liu D, Burkhart D, Cassino C, Kesten S. Bronchodilator responsiveness in patients with COPD. Eu Respir J 2008;31(4):742-750.

3. Gibson PG, Simpson JL. The overlap syndrome of asthma and COPD: what are its features and how important is it? Thorax 2009;64(8): 728-735.

4. Papi A, Romagnoli M, Baraldo S, Braccioni F, Guzzinati I, Saetta M, et al. Partial reversibility of airflow limitation and increased exhaled $\mathrm{NO}$ and sputum eosinophilia in chornic obstructive pulmonary disease. Am J Respir Crit Care Med 2000;162(5):1773-1777.

5. Halpin D, Peterson S, Larsson T, Calverly P. Identifying COPD patients at increased risk of mortality: Predictive value of clinical study baseline data. Respir Med 2008;102(11):1615-1624.

6. Brutsche MH, Downs SH, Schindler C, Gerbase MW, Schwartz J, Frey $\mathrm{M}$, et al. Bronchial hyperresponsiveness and the development of asthma and COPD in asymptomatic individuals: SAPALDIA Cohort Study. Thorax 2006;61(8):671-677.

7. Hospers J, Postma D, Rijcken B, Weiss ST, Schouten J. Histamine airway hyper-responsiveness and mortality from chronic obstructive pulmonary disease: a cohort study. Lancet 2000;356(9238):1313-1317.

8. Leigh R, Pizzichini MMM, Morris MM, Maltais F, Hargreave FE, Pizzichini E. Stable COPD: predicting benefit from high-dose inhaled corticosteroid treatment. Eur Respir J 2006;27(5):964-971

9. Mahler DA, Wire P, Horstman D, Chang Ch, Yates J, Fischer T, Shah T. Effectiveness of fluticasone propionate and salmeterol combination delivered via the diskus device in the treatment of chronic obstructive pulmonary disease. Am J Respir Crit Care Med 2002; 166(8):1084-1091.
10. Welte T, Miravitlles M, Hernandez P, Eriksson G, Peterson S, Polanowski T, Kessler R. Efficacy and tolerability of budesonide/ formoterol added to tiotropium in patients with chronic obstructive pulmonary disease. Am J Respir Crit Care Med 2009;180(8):741-750.

11. Ries AL, Bauldoff GS, Carlin BW, Casaburi R, Emery CF, Mahler $\mathrm{DA}$, et al. Pulmonary Rehabilitation. Joint ACCR/AACVPR evidence-based clinical practice guidelines. Chest 2007;131(5 suppl): S4-S42.

12. Ortega F, Toral J, Cejudo P, Villagomez R, Sánchez H, Castillo J, Montemayor T. Comparison of effects of strength and endurance training in patients with chronic obstructive pulmonary disease. Am J Respir Crit Care Med 2002;166(5):669-674.

13. American Thoracic Society. Lung function testing; selection of reference values and interpretative strategies. Am Rev Respir Dis 1991; 144(5):1202-1218

14. Global Initiative for Asthma (GINA). Global strategy for asthma management and prevention. NHLBI/WHO Workshop Report 2010. http://www.ginasthma.org/documents/5/documents_variants/35. Accessed November 4, 2013.

15. Pellegrino R, Viegi G, Brusasco V, Crapo RO, Burgos F, Casaburi $\mathrm{R}$, et al. Interpretative strategies for lung function tests. Eur Respir $\mathbf{J}$ 2005;26(5):948-968

16. American Thoracic Society; American College of Chest Physicians. ATS/ACCP statement on cardiopulmonary exercise testing. Am J Respir Crit Care Med 2003;167(2):211-277.

17. Maltais F, Leblanc P, Jobin J, Berube C, Bruneau J, Carrier L, et al Intensity of training and physiologic adaptation in patients with chronic obstructive pulmonary disease. Am J Respir Crit Care Med 1997;155(2):555-561.

18. Recomendaciones de la Sociedad Española de Neumología y Cirugía Torácica (SEPAR). Normativa para la espirometría forzada. Barcelona: Ed. Doyma; 1985. Article in Spanish.

19. Goldman HI, Becklake MR. Respiratory function test. Normal values at median attitudes and the prediction on normal results. Am Rev Tub 1959;79(4):457-467

20. Celli BR, Cote CG, Marin JM, Casanova C, Montes de Oca M, Mendez RA, et al. The body-mass index, airflow obstruction, dyspnea, and exercise capacity index in chronic obstructive pulmonary disease. N Engl J Med 2004;350(10):1005-1012.

21. Ortega F, Montemayor T, Sanchez A, Cabello F, Castillo J. Role of cardiopulmonary exercise testing and the criteria used to determine disability in patients with severe chronic obstructive pulmonary disease. Am J Respir Crit Care Med 1994;150(3):747-751.

22. Ward SA, Palange P. Clinical exercise testing. European respiratory monograph. Plymouth, UK: ERS; 2007.

23. Altose MD. Assessment and management of breathlessness. Chest 1985;88(2 Suppl):S77-S83.

24. Singh SJ, Morgan MD, Scott S, Walters D, Hardman AE. Development of a shuttle walking test of disability in patients with chronic airways obstruction. Thorax 1992;47(12):1019-1024.

25. Lillegard WA, Terrio JD. Appropriate strength training. Med Clin North Am 1994;78(2):457-477.

26. Mahler DA, Weinberg DH, Wells CK, Feinstein AR. The measurement of dyspnea. Contents, interobserver agreement, and physiologic correlates of two new clinical indexes. Chest 1984;85(6):751758.

27. Sweer L, Zwillich CW. Dyspnea in the patient with chronic obstructive pulmonary: etiology and management. Clin Chest Med 1990; 11(3):417-445.

28. Guyatt GH, Berman LB, Townsend M, Pugsley SO, Chambers LW. A measure of quality of life for clinical trials in chronic lung disease. Thorax 1987;42(10):733-778.

29. Guell R, Casan P, Sangenis M, Sentís J, Morante F, Borras JM, Guyatt G. The Spanish translation and evaluation of a quality-of-life 


\section{IMPACT OF BRONCHODILATOR RESPONSIVENESS ON QUALITY OF LIFE AND EXERCISE CAPACITY}

questionnaire in patients with chronic obstructive pulmonary disease. Arch Bronconeumol 1995;31(5):202-210.

30. Han MK, Agustí A, Calverley PM, Celli BR, Criner G, Curits JL, et al. Chronic obstructive pulmonary disease phenotypes: the future of COPD. Am J Respir Crit Care Med 2010;182(5):598-604.

31. Shaw DE, Berry MA, Hargadon B, McKenna S, Shelley Mj, Green $\mathrm{RH}$, et al. Association between neutrophilic airway inflammation and airflow limitation in adults with asthma. Chest 2007;132(6): 1871-1875.

32. Crapo RO, Casaburi R, Coates AL, Enright PL, Hankinson JL, Irvin $\mathrm{CG}$, et al. Guidelines for methacholine and exercise challenge testing - 1999. Am J Respir Crit Care Med 2000;161(1):309-329.

33. Brouillard C, Pepin V, Milot J, Lacasse Y, Maltais F. Endurance shuttle walking test: responsiveness to salmeterol in COPD. Eur Respir J 2008;31(3):579-584.

34. Pepin V, Saey D, Whittom F, LeBlanc P, Maltais F. Walking versus cycling. Sensitivity to bronchodilation in chronic obstructive pulmonary disease. Am J Respir Crit Care Med 2005;172(12): 1517-1522.

35. Pepin V, Brodeur J, Lacasse Y, Milot J, LeBlanc P, Whittom F, Maltais F. Six-minute walking versus shuttle walking: responsiveness to bronchodilation in chronic obstructive pulmonary disease. Thorax 2007;62(4):291-298.
36. Singh SJ, Jones PW, Evans R, Morgan MDL. Minimum clinically important improvement for the incremental shuttle walking test. Thorax 2008;63(9):775-7.

37. Oga T, Nishimura K, Tsukino M, Sato S, Hajiro T. Analysis of the factors related to mortality in chronic obstructive pulmonary disease: role of exercise capacity and health status. Am J Respir Crit Care Med 2003;167(4):544-549.

38. Cote CG, Pinto-Plata V, Kasprzyk K, Dordelly LJ, Celli BR. The 6-min walk distance, peak oxygen uptake, and mortality in COPD. Chest 2007;132(6):1778-1785.

39. Calverley PM, Burge PS, Spencer S, Anderson JA, Jones PW. Bronchodilator reversibility testing in chronic obstructive pulmonary disease. Thorax 2003;58(8):659-664.

40. Hurst JR, Vestbo J, Anzueto A. Susceptibility to exacerbation in chronic obstructive pulmonary disease. N Engl J Med 2010;363(12): 1128-1138.

41. de Torres JP, Pinto-Plata V, Ingenito E, Bagley P, Gray A, Berger R, Celli B. Power of outcome measurements to detect clinically significant changes in pulmonary rehabilitation of patients with COPD. Chest 2002;121(4):1092-8.

42. Johannessen A, Lehmann S, Omenaas ER, Eide GE, Bakke PS, Gulsvik A. Post-bronchodilator spirometry reference values in adults and implications for disease management. Am J Respir Crit Care Med 2006;173(12):1316-1325. 